\title{
ELEVATED SERUM LEVELS OF TNF SOLUBLE RECEPTORS IN PATIENTS WITH POSITIVE ANTI-NEUTROPHIL CYTOPLASMIC ANTIBODIES
}

\author{
P. ROUX-LOMBARD*, H.-C. LIN†, J. B. PETER $\dagger$ and J.-M. DAYER* \\ *Division of Immunology and Allergy, Department of Medicine, University Hospital, 1211 Geneva 14, \\ Switzerland and TSpecialty Laboratories, Inc. Santa Monica, California 90404-3900, USA
}

\begin{abstract}
SUMMARY
ANCA are found in various systemic vasculitis and are supposed to play a role in the pathogenesis of the disease, in cooperation with other factors such as cytokines. A total of 36 ANCA-positive and 10 ANCA-negative serum samples were analysed for the presence of TNF soluble receptors (TNF-sR), which are shed from the surface of activated cells and may act as TNF inhibitors. Of the ANCA-positive samples, $67 \%$ had elevated TNF-sR75 and $72 \%$ had elevated TNF-sR55 compared to ANCA-negative specimens (mean [S.E.] 18.7 [17.3] vs 3.6 [1.5] and $10.5[9.7] v s 1.9[0.7] \mathrm{ng} / \mathrm{ml}, P<0.01$ ). Elevation of TNF-sR in patients with ANCA suggests that cytokines and their inhibitors are involved in the pathogenesis of ANCA-associated autoimmune diseases.
\end{abstract}

KEY WORDS: TNF- $\alpha$, TNF soluble receptors, Anti-neutrophil cytoplasmic antibodies.

ANTINEUTROPHIL cytoplasmic antibodies, specific for constituents of neutrophil granules and monocyte lysosomes, are present in patients with various systemic vasculitis. Two main types of staining patterns were distinguished on ethanol-fixed neutrophils used as substrate for indirect immunofluorescence microscopy: the cytoplasmic (cANCA) and the perinuclear (pANCA) pattern. Most cANCA are raised against a serine protease, termed proteinase 3 (PR3) or myeloblastine, and are associated with Wegener's granulomatosis, whereas pANCA have specificity for myeloperoxidase or elastase and tend to be associated with idiopathic crescentic glomerulonephritis or necrotizing vasculitis other than Wegener's $[1,2]$. ANCA levels correlate closely with disease activity, and relapses of Wegener's granulomatosis are preceded by a rise of cANCA levels [3, 4]. It thus follows that ANCA may play a role in the pathogenesis of systemic vasculitis. Indeed, it has been shown in vitro that both cANCA and pANCA are able to activate neutrophil respiratory burst and degranulation and to enhance their chemotactic response to fMLP $[5,6]$. The resulting release of neutrophil proteases and reactive oxygen species may damage endothelial cells, leading to vascular necrosis. This neutrophil activation was most effective after priming neutrophils with TNF- $\alpha$, known to enhance the expression of adhesion molecules on neutrophils and vascular endothelial cells [5]. TNF binds to two distinct receptors of $55 \mathrm{kDa}$ (TNF-R55) and $75 \mathrm{kDa}$ (TNF-R75) [7], which are expressed in nearly identical amounts at the neutrophil surface [8]. Upon exposure to chemotactic factors, neutrophils shed their surface TNF-R and then release TNF soluble receptors (TNF-sR) which may act as TNF inhibitors $[8,9]$. We therefore tested sera for a possible

Submitted 8 October 1993; revised version accepted 1 February 1994. relationship between the presence of ANCA and the concentrations of TNF-sR and TNF- $\alpha$.

\section{MATERIALS AND METHODS}

\section{Serum specimens}

A total of 46 serum samples sent to the laboratory for ANCA analysis (19 cANCA-positive, 17 pANCApositive and 10 ANCA-negative) and 21 serum samples obtained from normal blood donors were analysed.

\section{ANCA determination}

ANCA concentrations were determined by flow cytometry using fixed neutrophils as targets [10]. ANCA-positive specimens were further characterized by indirect immunofluorescence to distinguish pANCA staining from cANCA staining $[5,11]$.

\section{TNF-sR measurement}

TNF-sR55 and TNF-sR75 were assayed by enzymelinked immunological biological assay (ELIBA; F Hoffmann-La Roche, Basel, Switzerland) as previously described [12]. Briefly, 96-well microtitre plates were coated with either monoclonal antibodies to TNF-sR55 (clone htr-20) or to TNF-sR75 (clone utr-4), and saturated with bovine serum albumin (Sigma Ltd, St Louis, MO). Microtitre plates were washed and $100 \mu$ l of standard (human recombinant TNF-sR55 and TNF-sR75), or diluted samples were dispensed onto the plates. Horseradish peroxidase-conjugated human recombinant TNF- $\alpha$ was added to the wells, and plates were incubated overnight at room temperature in a single-step reaction. After washing, tetramethylbenzidine $\mathrm{H}_{2} \mathrm{O}_{2}$ was added and incubated for $15 \mathrm{~min}$. The reaction was stopped with $\mathrm{H}_{2} \mathrm{SO}_{4}$ and absorption read at $450 \mathrm{~nm}$. The concentrations of TNF-sR55 and TNF-sR75 in the samples were determined by interpol- 
ation from the standard curve. The addition of up to $10 \mathrm{ng} / \mathrm{ml}$ of recombinant human TNF- $\alpha$ had no effect on the TNF-sR assay, the sensitivity of which was $150 \mathrm{pg} / \mathrm{ml}$.

\section{TNF- $\alpha$ measurement}

A commercially available ELISA was used to measure TNF- $\alpha$ (TNF- $\alpha$ EASIA; Medgenix Ltd, Fleurus, Belgium). Preliminary experiments showed that TNF- $\alpha$ determinations were similar in the presence of various concentrations of both types of human recombinant TNF-sR (up to $15 \mathrm{ng} / \mathrm{ml}$ for hrTNF-sR75 and up to $10 \mathrm{ng} / \mathrm{ml}$ for hrTNF-sR55) as in buffer in this assay (Table I). We assume therefore that the totality of TNF- $\alpha$ present in serum, both free and bound to TNF-sR, was measured and that the immunoassay was not hampered by the presence of high levels of TNFsR55 or TNF-sR75.

\section{IL-8 measurement}

IL-8 was assayed by a commercially available ELISA (Research and Diagnostic Systems, Minneapolis, MN, USA) according to the supplier's instructions.

\section{Statistics}

Results are expressed as mean \pm S.D. Data were subjected to the Kruskal-Wallis analysis of variance and Bonferroni equality test.

\section{RESULTS}

ANCA-positive sera - consisting of CANCA and pANCA - contained significantly higher concentrations of TNF-sR55 $(10.5 \pm 9.7 \mathrm{ng} / \mathrm{ml})$ and TNF-sR75 $(18.7 \pm 17.3 \mathrm{ng} / \mathrm{ml})$ than normal sera obtained from healthy blood donors $(1.6 \pm 0.3$ and $2.1 \pm 0.5 \mathrm{ng} / \mathrm{ml}$ of TNF-sR55 and TNF-sR75, respectively) $(P<0.01)$. The elevation of TNF-sR concentrations was also significant as compared to ANCA-negative samples submitted for ANCA analysis $(1.9 \pm 0.7$ and $3.6 \pm 1.5 \mathrm{ng} / \mathrm{ml}$ of TNF-sR55 and TNF-sR75, respectively) $(P<0.01)$. When ANCA-positive sera were discriminated according to their immunofluorescence pattern, pANCA-positive sera contained six- to sevenfold higher concentrations of both TNF-sR55 $(13.2 \pm 9.7 \mathrm{ng} / \mathrm{ml}) \quad(P<0.01) \quad$ and $\quad$ TNF-sR75
$(25.1 \pm 16.8) \quad(P<0.01)$ than did ANCA-negative samples, while the increase in cANCA-positive sera was less striking $(8.0 \pm 9.2$ and $13.0 \pm 16.0 \mathrm{ng} / \mathrm{ml}$ of TNF-sR55 and TNF-sR75, respectively) but nevertheless statistically significant for TNF-sR55 $(P<0.05)$ (Fig. 1, upper and middle panels). In addition, a higher percentage of patients positive for pANCA showed elevated levels of TNF-sR55 and TNF-sR75 as compared to patients positive for CANCA (82 vs $53 \%$, and 82 vs $63 \%$, respectively), elevated level being defined as a value above mean + 2 s.D. of ANCA-negative samples. However, there was no relationship between ANCA concentrations as defined by fluorescence intensity and TNF-sR concentrations in serum (data not shown).

High TNF- $\alpha$ levels were also observed in both ANCA-positive groups, however without any clear correlation with TNF-sR levels. Elevated TNF- $\alpha$ in two ANCA-negative patients as compared to normal sera suggested an ANCA-unrelated inflammatory process (Fig. 1, lower panel).

\section{DISCUSSION}

The finding of a close correlation between the pres ence of ANCA and elevated levels of both types of TNF-sR in vasculitis serum provides additional evidence of the role of ANCA in the pathogenesis of vasculitis. It strongly suggests that ANCA-induced neutrophil activation that was demonstrated in vitro [5, 6] also occurs in vivo. It is likely that ANCA-induced neutrophil degranulation and release of proteolytic enzymes, such as elastase - known to cleave TNF receptors [8] - lead to the shedding of TNF-sR from the neutrophil surface. It is also possible that the intracellular pool of TNF-R55 located in neutrophil-specific granules is a source of TNF-sR55 released after degranulation [13]. However, both types of TNF-sR are increased in ANCA-positive sera and there was a positive correlation between them, suggesting that the latter mechanism was not the main source of TNF-sR in these sera.

TNF-sR levels determined in ANCA-positive sera were remarkably elevated as compared to those measured in chronic rheumatic diseases such as RA (range of TNF-sR55 : $1.0-2.7 \mathrm{ng} / \mathrm{ml}$ and range of TNF-

TABLE I

Effect of the addition of TNF-sR on TNF- $\alpha$ levels

\begin{tabular}{|c|c|c|c|c|c|c|c|c|c|c|c|c|c|}
\hline \multirow{3}{*}{$\begin{array}{c}\mathrm{hrTNF}-\alpha \\
(\mathrm{pg} / \mathrm{ml})\end{array}$} & \multicolumn{13}{|c|}{ TNF- $\alpha$ levels $(\mathrm{pg} / \mathrm{ml})$ in the presence of hrTNF-sR55 and -sR75 $(\mathrm{ng} / \mathrm{ml})$} \\
\hline & \multirow[b]{2}{*}{ Buffer } & sR55 & sR75 & sR55 & sR75 & sR55 & sR75 & sR55 & sR75 & sR55 & sR75 & sR55 & sR75 \\
\hline & & \multicolumn{2}{|c|}{0.65} & \multicolumn{2}{|c|}{1.25} & \multicolumn{2}{|c|}{2.5} & \multicolumn{2}{|c|}{5} & \multicolumn{2}{|c|}{10} & \multicolumn{2}{|c|}{15} \\
\hline 0 & 0 & 0 & 0 & 0 & 0 & 14 & 0 & 0 & 0 & 0 & 0 & n.d. & \\
\hline 7.5 & 3 & 3 & 3 & 3 & 4 & 4 & 3 & 6 & 4 & 6 & 5 & n.d. & 5 \\
\hline 25 & 15 & 17 & 15 & 14 & 16 & 17 & 24 & 18 & 17 & 22 & 16 & n.d. & 17 \\
\hline 75 & 54 & 53 & 43 & 45 & 54 & 50 & 50 & 54 & 52 & 58 & 55 & n.d. & 49 \\
\hline 250 & 183 & 186 & 118 & 182 & 173 & 169 & 179 & 191 & 214 & 209 & 193 & n.d. & 217 \\
\hline 750 & 606 & 597 & 443 & 595 & 569 & 547 & 582 & 566 & 558 & 606 & 538 & n.d. & 663 \\
\hline
\end{tabular}

TNF- $\alpha$ levels were measured in the presence of hrTNF-sR buffer and of increasing concentrations of both types of hrTNF-sR, using the Medgenix TNF- $\alpha$ EASIA.

n.d., Not done. 


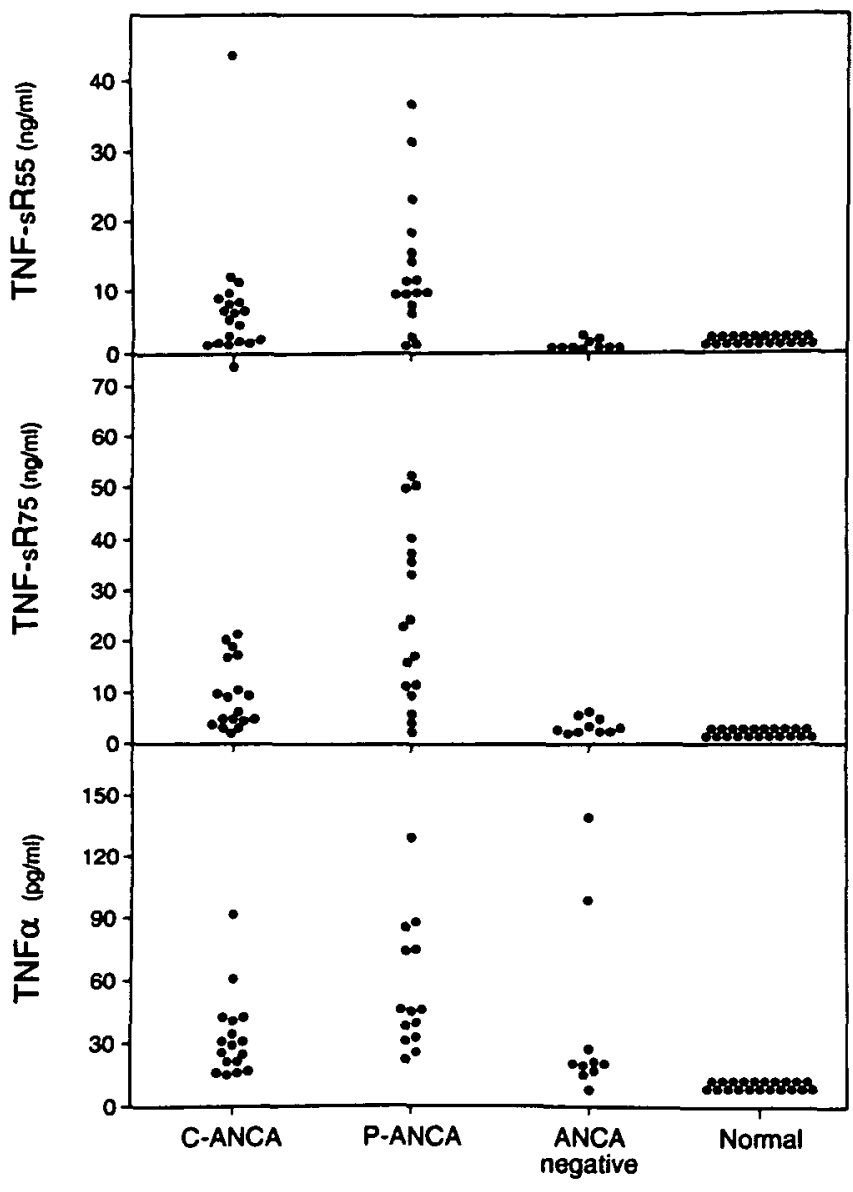

FiG. 1.-Levels of TNF-sR55 (upper panel), TNF-sR75 (middle panel) and TNF- $\alpha$ (lower panel) in cANCA-positive $(n=19)$, pANCA-positive $(n=17)$, ANCA-negative $(n=10)$ and normal $(n=21)$ serum samples.

sR75 : $2.5-6.8 \mathrm{ng} / \mathrm{ml})[12,14]$ or polymyositis $(1.1-$ $7.5 \mathrm{ng} / \mathrm{ml}$ and $3.0-16.1 \mathrm{ng} / \mathrm{ml}$ ) (manuscript in preparation). However, levels of TNF-sR reached in ANCA-positive sera remained below the ones we observed in meningococcaemia $(5-136 \mathrm{ng} / \mathrm{ml}$ and 10 $145 \mathrm{ng} / \mathrm{ml})[15,16]$. Further studies will be necessary to accurately compare TNF-sR levels in various chronic diseases and to assess whether there is a relationship with the pathogenesis or with the course of the disease.

TNF-sR released after neutrophil degranulation may compete for TNF- $\alpha$ with TNF cell surface receptors on other neutrophils as well as on surrounding endothelial cells $[2,17]$ and thus act as a TNF- $\alpha$ antagonist [18], protecting the cells against further activation and toxicity of high levels of TNF- $\alpha$. On the other hand, TNF-sR have been shown in vitro to preserve TNF- $\alpha$ activity by stabilizing its trimeric structure [19] and may thus contribute to the amplification of ANCA-mediated neutrophil activation. These dual activities of TNF-sR might explain why we did not find a clear correlation between TNF-sR levels and ANCA concentrations.

A recent study revealed elevated TNF- $\alpha$ levels in the serum of Wegener's patients during the active phase and their absence during remission [17]. Those results are not inconsistent with our findings, since ANCApositive sera were obtained from patients at different stages of the disease and we did not investigate the relationship between TNF-sR levels and disease activity. The presence of TNF-sR55 or -sR75 did not impair TNF- $\alpha$ determination by the ELISA we used; therefore, low levels of TNF- $\alpha$ detected in serum could not be imputed to interferences with soluble receptors. It is more likely that a transient increase in TNF- $\alpha$, which is able to prime neutrophils and to enhance ANCAinduced neutrophil activation $[5,6]$, may have escaped detection due to the short half-life of TNF- $\alpha$, but nevertheless triggered an elevation of TNF-sR concentrations remaining in the serum for prolonged periods.

Two recent studies demonstrate that serum levels of another soluble receptor - IL-2 soluble receptor (IL-2sR) - correlate with disease activity in patients with Wegener's granulomatosis $[20,21]$. However, the presence of IL-2sR has a completely different significance since it is mainly a marker of T cell activation and does not have a proven inhibitory effect on IL-2 activity [22].

Upon exposure to TNF- $\alpha$ or interleukin-1, endothelial cells, fibroblasts and other cell types produce IL-8 which is one of the main chemoattractants for neutrophils [23]. In addition, IL-8 along with TNF- $\alpha$ promotes the translocation of PR3 from their intragranular loci to the neutrophil surface and then renders the autoantigen accessible to ANCA [2]. IL-8 is therefore likely to be involved in ANCA-mediated pathogenesis of vasculitis. However, in preliminary experiments, elevated levels of IL-8 were detectable in few ANCA-positive sera (five of 15 pANCA and six of 17 cANCA). None of the ANCA-negative sera contained IL- 8 concentrations above the limit of detection $(93 \mathrm{pg} / \mathrm{ml})$. No correlation was found between IL-8 TNF- $\alpha$ levels or between IL- 8 and TNF-sR levels (data not shown). This may be due to the fact that IL- 8 acts mainly at the local level and does not circulate at concentrations detectable by the immunoassay we have used. It is also possible that IL-8 was elevated only during the initial phase of the vasculitis and no longer detectable in our specimens obtained at different stages of the disease.

Although there is still no direct evidence to demonstrate the pathogenic effect of ANCA in vivo, the presence of elevated levels of TNF-sR in ANCA-positive serum is an important element in the understanding of the pathogenesis of some systemic vasculitides. The balance between TNF- $\alpha$ and TNF-sR is probably a critical factor in the pathophysiological process, but further investigations and prospective studies will be necessary to fully understand its role and its relationship with disease activity.

\section{ACKNOWLEDGEMENTS}

This study was supported by grant 31-33786.92 from the Swiss National Science Foundation. We thank Mrs C. de Luca for excellent technical assistance and Mrs B. Mermillod for help with the statistical analysis.

\section{REFERENCES}

1. Kallenberg CGM, Cohen Tervaert JW, van der Woude 
FJ, Goldschmeding R, Kr. von dem Borne AEG, Weening JJ. Autoimmunity to lysosomal enzymes: new clues to vasculitis? Immunol Today 1991;12:61-4.

2. Gross WL, Schmitt WH, Csernok E. ANCA and associated diseases: immunodiagnostic and pathogenetic aspects. Clin Exp Immunol 1993;1:1-12.

3. Gross WL, Ludemann G, Kiefer G, Lehmann H. Anticytoplasmic antibodies in Wegener's granulomatosis. Lancet 1986;i:806 (letter).

4. Cohen Tervaert JW, van der Woude FJ, Fauci AS et al. Association between active Wegener's granulomatosis and anticytoplasmic antibodies. Arch Intern Med 1989;149:2461-5.

5. Falk RJ, Terrell RS, Charles LA, Jennette JC. Antineutrophil cytoplasmic autoantibodies induce neutrophils to degranulate and produce oxygen radicals in vitro. Proc Natl Acad Sci USA 1990;87:4115-9.

6. Keogan MT, Esnault VLM, Green AJ et al. Activation of normal neutrophils by antineutrophil cytoplasm antibodies. Clin Exp Immunol 1992;90:228-34.

7. Brockhaus M, Schoenfeld HJ, Schlaeger EJ, Hunziker W, Lesslauer W, Loetscher H. Identification of 2 types of tumor necrosis factor receptors on human cell lines by monoclonal antibodies. Proc Natl Acad Sci USA 1990;87:3127-31.

8. Porteu F, Brockhaus M, Wallach D, Engelmann $H$, Nathan CF. Human neutrophil elastase releases a ligand-binding fragment from the $75 \mathrm{kD}$ tumor necrosis factor (TNF) receptor. Comparison with the proteolytic activity responsible for shedding of TNF receptors from stimulated neutrophils. $J$ Biol Chem 1991;266:20131-8.

9. Porteu F, Nathan CF. Shedding of tumor necrosis factor receptors by activated human neutrophils. $J$ Exp Med 1990;172:599-607.

10. Peter JB, Wormsley SB, Dawkins RL. Antineutrophil cytoplasm antibodies (ANCA) in systemic vasculitis : clinical utility of quantitation by flow cytometry. Neurology 1988;38 (suppl. 1):99.

11. Nölle B, Specks U, Lüdemann J, Rohrbach MS, DeRemee RA, Gross WL. Anticytoplasmic autoantibodies : their immunodiagnostic value in Wegener's granulomatosis. Ann Intern Med 1989;111:28-40.

12. Roux-Lombard P, Punzi L, Hasler F et al. Soluble tumor necrosis factor receptors in human inflammatory synovial fluids. Arthritis Rheum 1993;36:485-9.

13. Porteu F, Nathan C. Mobilizable intracellular pool of p55 (type I) tumor necrosis factor receptors in human neutrophils. J Leukoc Biol 1992;52:122-4.

14. Guerne PA, Cekir N, Moral F et al. Levels of TNF soluble receptors are markedly elevated in systemic lupus erythematosus in contrast to rheumatoid arthritis. Highly significant correlation with disease activity. Arthritis Rheum 1993;36 (suppl. 9):S147.

15. Girardin E, Roux-Lombard P, Grau GE et al. Imbalance between tumor necrosis factor $\alpha$ and soluble TNF receptor concentrations in severe meningococcemia. Immunology 1992;76:20-23.

16. Villard J, Roux-Lombard P, Hugli A, Dayer JM. Could natural inhibitors of tumor necrosis factor $\alpha$ modify the clinical course of fulminant meningococcemia? Crit Care Med 1993;21:1396-400.

17. Gross WL, Csernok E, Schmitt WH. Antineutrophil cytoplasmic autoantibodies: immunobiological aspects. Klin Wochenschr 1991;69:558-66.

18. Seckinger $\mathrm{P}$, Zhang JH, Hauptmann B, Dayer JM. Characterization of a tumor necrosis factor-alpha (TNF-alpha) inhibitor - Evidence of immunological crossreactivity with the TNF receptor. Proc Natl Acad Sci USA 1990;87:5188-92.

19. Aderka D, Engelmann H, Maor Y, Brakebusch C, Wallach D. Stabilization of the bioactivity of tumor necrosis factor by its soluble receptors. $J$ Exp Med 1992;175:323-9.

20. Schmitt WH, Heesen C, Csernok E, Rautmann A, Gross WL. Elevated serum levels of soluble interleukin-2 receptor in patients with Wegener's granulomatosis. Arthritis Rheum 1992;35:1088-96.

21. Stegeman CA, Cohen Tervaert JW, Huitema MG, Kallenberg CGM. Serum markers of $T$ cell activation in relapses of Wegener's granulomatosis. Clin Exp Immunol 1993;91:415-20.

22. Fernandez-Botran R. Soluble cytokine receptors : their role in immunoregulation. FASEB J 1991; 5:2567-74

23. Baggiolini M, Clark Lewis I. Interleukin-8, a chemotactic and inflammatory cytokine. FEBS Lett 1992;307: 97-101. 